\title{
Fostering Learner Mobility Between Engineering Education and a Twenty First Century Workplace
}

\author{
doi:10.3991/ijac.v4i2.1636 \\ Akram Abu-aisheh and Lynroy Grant \\ University of HartfordWest Harford, CT, USA
}

\begin{abstract}
Engineering education today is undergoing unprecedented array of challenges, especially in the teaching and learning process. Among other challenges in this area students now require multiple stimuli, they have very low tolerance for monotonous static content, and they are highly mobile. To address some of these challenges, the authors have conducted a pilot study with Learner Agent Objects (LAO) individual portfolios. LAO portfolios are collections of artifacts (students' best work) representing a learner's academic experience. LAO affords a foundation for creating a more comprehensive and seamless movement of learners between jurisdictions in engineering education and the workplace. A more seamless movement of individuals between formal education, informal education and the workplace has significant implications for the learning environments and ecosystems of engineers as lifelong learners.
\end{abstract}

Index Terms-Learner Agent Object, Learner Mobility, Learning Environments and Ecosystems.

\section{INTRODUCTION}

Technology has engendered many successful advances in engineering education, and higher education in general, but also has created urgency for new interdisciplinary arrangements, and tools, for sustaining the mobility a digital teaching and learning environment affords. For example it is still a cumbersome, expensive and opaque process for individuals to navigate issues of economics, of competing interests, of autonomy and of different stakeholders in engineering education infrastructure.

The search for more seamless collaborations is not unique to engineering education. For example, economics is a significant source of interdisciplinary knowledge for the other social sciences and business, but such knowledge is approached with suspicion when no area of economics appears to build substantially on insights from its sister disciplines [1]. There are many research efforts to capitalize new technological advances toward improving seamless interdisciplinary collaborations. One example, from among many, is to explore alternative teaching and learning environments and ecosystems in which the National Science Foundation (NSF) and the journal Science created the International Science and Engineering Visualization competition as a way of promoting alternative forms of communicating science, engineering and technology for education and journalistic purposes, [2-3].

Another example is the collaboration of many institutions to explore opportunities of Open Courseware. However, these partnerships have been generally reactive, piecemeal, and have not resulted in major systemic change for a seamless movement of individuals within K-16 engi- neering education infrastructure and beyond to lifelong learning as informed citizens.

The purpose of this pilot study is to explore a proof of concept how to capitalize on available technology for creating a more comprehensive and seamless environment which links academic experiences of students from selected CETA classes: between formal settings and nonformal learning, and also between classroom experiences and the workplace.

This study is based on the assumption that cumulative artifacts, simulations, and metadata can represent and influence an individual's learning experiences both in and out of the formal engineering education setting. The study has used Blackboard as container for students' best versions of class assignments called Learner Agent Objects (LAO) individual portfolios. Frequency of access to these documents was used as indicator of student interest, and content of data files were reviewed to measure level of student collaboration. Preliminary results indicated that LAO individual portfolios increased time-on-task and increased emotional investment in quality of class assignments.

The study has raised important questions that require more conversations and research. For example more work is needed to study Personal Digital Containers of Cumulative Knowledge (PDCoCK) system which cultivates cumulative artifacts, simulations, and metadata representing and influencing an individual's learning experiences both in and out of formal K-16 engineering education setting. This limited work only highlight the possibility that LAO could be a useful tool for accommodating transparent collaboration between the different academic traditions in STEM education as technology continues to enabling unprecedented changes in our lives.

\section{LEARNER MOBILITY}

The Literature shows strong relationship between timeon-task and positive learning outcomes [4-5]. Also a Learning Processes Task Group from the National Mathematics Advisory Panel of the Department of Education [6] concluded that curricula should provide sufficient time on task to ensure acquisition and long term retention of both conceptual and procedural knowledge. While there may be consensus about the value of time-on-task in engineering education finding a solution has proven elusive for a number of reasons. For example, the limited time students spend engaged with formal learning activities. Donovan et al., [7] estimates students spend about $14 \%$ of their day in school.

Many believe timeline recommendation for engineering education is unrealistic. In reference to reports such as 
Gathering Storm [8], Engineer of 2020 [9], and How People Learn: Bridging Research and Practice [10], Karen Watson observes that the engineer of 2020 is already in sixth grade, and because universities curricula generally change slowly the recommended goals are unrealistic. "It is going to take course changes, content changes, pedagogical changes, organizational changes, structural changes and cultural changes to realize systems to educate the engineer of 2020" [11]. In addition, the many stakeholders involved in preparing future engineer, and technologists, makes change a complex endeavor given that "technical and non-technical issues are inextricable and increasingly linked" [12]. The complexities of these interconnectivities raise a specter and frustration in process in search of meeting critical competencies recommended in these reports.

There are many other aspects to achieving 2020 forecasted critical competencies [13]. For example, keeping alumni and the country's workforce up-to-date with current competencies is just as important as reconfiguring our universities in preparation for the next generation of engineers. The spirit of these reports is not just to create one cohort of engineer and technologists for 2020 but instead to upgrade, and maintain, our workforce critical competencies. Finding a common way of communicating successes in useful formats for all stakeholders, while communicating important lessons of failed efforts we can learn from, is one common challenge among all stakeholders in engineering education.

One aspect of this challenge of collaboration in engineering education is bringing expert knowledge of one discipline in contact with expert knowledge of another discipline. This is particularly true in science, technology, engineering, and mathematics (STEM) education given its role as foundations of, and gateway to, engineering education efforts in preparing future technologists, and engineers for solving multidisciplinary problems of the future [8]. However, this is not unique to STEM education. According to Pieters and Baumgartner, even within the same discipline sharing expert knowledge is a challenge. "No area of economics appears to build substantially on insights from its sister disciplines" [14].

In general, the spirit of the literature indicates that pedagogical solutions to the challenges of STEM education is of significant importance not only to educators, students, and administrators, but also very important to policy makers, and critical to maintaining the country's workforce. The implication is that any solution should provide seamless collaboration among stakeholders with diverse academic traditions with different ways of knowing, aspirations, and interpretations of knowledge [15].

This paper describes Learner Agent Objects (LAO) as a potential tool for improving student mobility in STEM education. LAO capitalizes on available (off the shelf) technology to create a more comprehensive and seamless environment for linking academic experiences of students: between formal settings and non-formal learning, and also between classroom experiences and the workplace. The goal is to explore proof-of-concept that cumulative artifacts, simulations, and metadata can represent and influence an individual's learning experiences both in and out of the formal engineering education setting thereby serving as the foundation for a more transparent cumulative knowledge base for engineering education of the $21^{\text {st }}$ century.
The paper concludes with results from an ongoing exploratory study using Blackboard discussion to represent digital containers of artifacts and simulations of CETA students' academic experiences. The remainder of the paper is organized as follows. First, the exploratory study and research methodology is reviewed. Next, results from the exploratory study are discussed, followed by the conclusions and implications of these results given at the end of the paper.

\section{The LEARnER AgENT OBJeCTIVE FramewORK}

Learner Agent Objects (LAO) is not a specific technology or pedagogical methodology instead it is a framework of ideas for creating and transferring knowledge in a digital environment where the capability of the student (learner) transcends biology [16]. LAO aims to use the affordance of digital technology to extend our perception of the individual's capabilities to learn, work and make decision as an informed citizen. This affordance includes continuously accumulating academic artifacts, and simulations, in a permanent personal library for supporting the individual's interaction with stakeholders in the teaching and learning process. Support capabilities are grouped in at least three categories:

1. in artifacts, simulations, and metadata that represent and influence an individual's learning experiences both in and out of the formal engineering education,

2. in exchanging ideas with others,

3 . in analyzing and solving problems. One assumption is that over time and as digital technology matures, the usefulness of this personal library or hub of knowledge would render it an extension of the individual much as a limb or organ in the teaching and learning process.

LAO is grounded in a long history of successful, but piecemeal efforts, among the disciplines in STEM education. Some of these successful but piecemeal education efforts are: First Year Interest Groups (FIG); intelligent learning systems; object-orientated education technology and related interconnectivity applications; project based learning and active learning methods; Increase application of market principles in education; philosophy and ethics for digital education enterprises; and heightened interest in understanding how people learn [7]. Students (learners) are generally the only consistently common element in these piecemeal efforts, and for learners to be capable of presenting more complete information about their academic situation to stakeholders in STEM education is the focus of LAO.

The LAO framework draws heavily from a category of FIGs, implemented at the University of Hartford and other locations, which by design uses existing infrastructures (both physical and epistemological) to support small curricular units called Integrated Learning Blocks (ILB). However, in the wake of a critical cohort of maturing technologies reaching a practical tipping point, tools from instructional technology, computer and cognitive sciences are employed to expand the ILB concept into smart continuous learning agents. In this project, LAOs expands the one-year FIG model to include pre-college experience and the entire college years, and continues with life beyond college. Developing an LAO infrastructure provides a valuable academic hub and scaffolding for supporting life- 
long learning and also the potential for creating new revenue streams for higher education.

LAO raises important philosophical issues about its usefulness in creating knowledge and ethics of a digitally extended student (learner) in a digital environment. For example, issues of control digital property, and compatibility. However, knowledge associated with this academic experience and other important philosophical issues are not the focus of this paper.

In addition, issues of LAO as a smart agent of the individual in a digital environment are also not the focus of this paper, and are best pursued elsewhere using existing agency theory research as a starting point for understanding issues of $\mathrm{LAO}$ as a digital agent of the individual learner. This is only a beginning attempt of a first step towards constructing a framework of ideas search for solutions about how to perceive enhanced learning, and enhanced learners, in three broad areas.

1. To prepare future technologists,

2. To prepare future engineers, and

3. To provide a timely delivery system for educating the country's workforce. To demonstrate the proof-ofconcept of LAO in these three categories, Blackboard discussion board was used as a digital container where students continuously accumulate their best work from selected classes.

\section{Data And Methodology}

The content of the student work posted on Blackboard forms a library of reusable objects (fixed) for subsequent exams, assignments, and future classes. For example, from Course Statistics on Blackboard it researchers were able to determine that students, and alumni, are using their post years after course.

An ethnographic exploratory study was started in the fall semester 2006 to test the concept of The Learner Agent Objects (LAO). Students from classes taught by selected faculty members (technical mathematics and electrical engineering) were asked initially to post their "best work" in three-ring binders used in formats required for Accreditation Board for the Engineering and Technology (ABET). However after one semester three-ring binders were replaced with posting students' "best work" on Blackboard where it could be observed by other students, faculty and staff. As of January 2009, the number of participants in the study is 200. Participants taking multiple courses were counted once.

Rubrics for class assignments and tests were created for the LAO framework for each class. In general, tests and class assignments were returned to the students with a grade. However, grades are not official until students make the necessary corrections to their work and post the edited content (best work) on Blackboard (grades are not included). Because of the limitations of the drop-box feature, a separate Blackboard class was created with one discussion board for all students to share their work. Each student would create one thread with their names, and then reply to their names attaching a file with their best work (Microsoft Word, text, graphics, videos, or PDF files). Each file on average contains material covered in a major topic or chapter of the textbook. For example, one file may contain three completed problems from each section of a textbook chapter, with full explanations of each step.
High level of expertise is expected from the student who presents his or her best work. That is, the focus is not on the source of the content, or what help the student received compiling the content but instead the focus is placed on how well the student can explain and can apply the content that is presented. For this study, students are expects to be tested at any time, and in different forms, about the material they post on Blackboard. This expectation of mastery, or ownership, of posted material is not just confined to one faculty, or students in the class, but to others involved in the academic life of the student.

Training is provided on how to use textbooks and other resources. For examples, training involves learning to read the examples in the text first before doing the exercises. Also, when reading examples in a textbook don't assume understanding of the problem until you copy the problem, and then do the problem without peeking. Training also involves learning how to maintain, and apply content to other related areas. For example, helping the student combine different class contents, and content from other disciplines, into a continuous and meaningful whole.

Faculty members are encouraged to use the posting on Blackboard as one way of understanding the academic history of their student, as well as using the posted material as a way of linking to what students already know. Not only works of students are posted in the area but sample solutions by faculty and other reference material is also posted.

Initially, the number of one-on-one student teacher conference relating to these activities increased by more than $70 \%$ with conference time averaging 25 minutes. Since the initial semester, student conferences have been decreasing by an average of $4.8 \%$ each semester, with the average time of conferences decreasing by $6 \%$ each semester. In September 2008 the average conference time 15 minutes. A conference management system was used to track details of the conferences (purpose of conference, start time, stop time, comments, location, number of students etc.).

\section{PREMILINARY RESUltS}

Using primitive or static LAO artifacts (Microsoft Word, PDF and Text files) to represent best work of selected CERA (400) generated significant student to student, and faculty-to-student activity in relation to what the literature considered seven best practices in teaching [1719]:

1. Increasing faculty-student interaction. Facultystudent interaction tends to be shorter but more frequent. Major reasons for the interactions include acting as referee for competing ideas in class projects, as consultant in solving a mathematics problem, and as a negotiator with students working for a better grade.

2. Fostering collaboration among students and providing prompt feedback. Students perceive having casual conversation about technical mathematics problem with their peers as exotic enough to merits curious inquiry. Patterns of understanding course content sometimes display a "viral" effect similar to YouTube or Wikipedia, and are more effective in communicating some technical ideas than traditional approaches. 
3. Encouraging active learning and emphasize time on task. Posting best work encourages more active participation in class work, increase attention to details, and add more relevance to technical mathematics.

4. Communicating high expectations while addressing different learning styles. The idea of posting class assignment after they are graded and edited allows students with different learning styles to produce the same high quality products.

Before the end of the first semester student activities quickly took on a combined YouTube and Wikipedia effect where posting best work from class assignments, special projects, and related materials became a symbol of competitive pride, a focus of social drama, and academic collaborations across subject areas and some university programs.

Some examples of social dramas include:

1. Student would challenge other ability to do the work they posted. As such posting class content brought social status, but also the responsibility of justifying one's knowledge of the subject.

2. Communication about what was covered in previous class improved, given that samples of the material were accessible and available to all interested parties in the teaching and learning process.

3. Time on task improved as measured by the Blackboard statistics. Student used the area all hours of the day with 12 hours before classes recording the highest usage.

Samples of collaboration include the following:

1. Students working with each other have increased. From observation, conversation about posting work, or asking question about work posted and other out of class activities start occurring only after students start posting their work on Blackboard and realized they are actually writing questions for their own examination.

2. Student-student interaction about class content increased significantly, and some questions that were directed at faculty are directed to other students leaving space for different questions and issues for the faculty to handle. In addition, with their work posted on Blackboard students find it easier to find other pedagogical resources.

3. Maintaining and atmosphere of individualized on demand instruction require extra time and resources. The same energy that motivates students to collaborate can quickly become distracting if faculty or qualified resources are not available to adjudicate conflicts, lack of information or other related issues.

4. Having libraries of students' best work also improves collaboration among faculty and staff. For example, students who are having problem for one reason or another generally post less work.

Prelimary results from CETA LAO pilot study using Blackboard shows:

1. Increasing faculty-student interaction,

2. Improved student-to-student collaboration leading to a "viral" effect similar to YouTube or Wikipedia which is more effective in communicating some technical ideas than traditional approaches.
3. Encouraging active learning and emphasize time on task.

4. Communicating high expectations while addressing different learning styles.

LAO is a work in progress, and more work is needed to document the full benefits smart learner agents bring to all areas of our digitized academic environment. Preliminary in the area of research, using data from CETA student on Blackboard demonstrates LAO's proof of concept in five general areas:

1. Reduce piecemeal fragmentations in education towards a seamless whole,

2. Create echo systems of sharable best practices (including ethics),

3. Provide better costs analysis in education,

4. Create new higher education revenue streams and

5. Enable interdisciplinary stakeholders of the learner to collaborate in their native academic ways of knowing and doing in the education process.

\section{CONCLUSION}

This study introduced the concept of LAO as a digital container for artifacts and simulations of CETA students (learners) academic experiences as only the beginning of a first step in a long process of research, conversations and negotiations towards a fundamental understanding of designing learning environments for future engineers that create the output we desire.

The results from this exploratory study shows proof of concept that LAO has potential for improving STEM education in five general areas:

1. Improves collaboration between selected technical mathematics and electrical engineering education towards a seamless whole,

2. Create echo systems of sharable best practices (including ethics or collaboration in a digital education environment),

3. Change pedagogical relationships in the teaching and learning process,

4. Demonstrates potential for creating new higher education revenue streams and

5. Enable interdisciplinary stakeholders of the learner to collaborate in their native academic ways of knowing and doing in the education process.

The study also indicates that the LAO's framework has implications on different levels in the teaching and learning process [20-22]. At the classroom level, students are encouraged to use appropriate (native) technology for communication their understanding of content. At the intuitional and community levels the LAO framework provides building blocks for multidisciplinary collaboration while affirming native academic dialects and ways of knowing, diverse interests, and multiple levels of participants. This shared system of best work evolves throughout the learner's academic life-cycle and creates a practical way for integrating lifelong SETM learning into our current higher education system.

\section{REFERENCES}

[1] Pieters, Rik, and Baumgartner, Hans. (2002). "Who Talks to Whom? Intra- and Interdisciplinary Communication of Economics 
Journals". Journal of Economic Literature: 40(2), pp. 483-509. doi: $10.1257 / 002205102320161348$

[2] Alabanese M., \& Mitchell, S. "Problem-based learning: a review of literature on its outcomes and implementation issues," Academic Medicine, Vol. 68, 1993, No. 1.

[3] Baker, D. A., \& Witt, P. A. (1995). Evaluation of the impact of two after-school programs. Journal of Park and Recreation Administration, 14(3), 60-81.

[4] Huang, R. X., M. A. Cane, N. Naik, and P. Goodman (2000), Global adjustment of the thermocline in response to deepwater formation, Geophys. Res. Lett., 27(6), 759-762. doi:10.1029/ 1999GL002365

[5] Wang, M. C., Haertel, G. D., \& Walberg, H. J. (1993). Toward a knowledge base for school learning. Review of Educational Research, 63(3), 249-294.

[6] Learning Processes Task Group. (2007). National Mathematics Advisory Panel Progress Report. United States Department of Education.

[7] Donovan, Suzanne, John D. Bransford, and James W. Pellegrino, (Eds.). How people learn: bridging research and practice. Committee on Learning Research and Educational Practice, Commission on Behavioral and Social Sciences and Education, National Research Council.

[8] National Research Council, Rising above the gathering storm: Energizing and employing America for a brighter economic future, Washington, DC: National Academies Press, 2005.

[9] National Academy of Engineering, The engineer of 2020, Washington, DC: National Academies Press. 2004.

[10] National Academy of Engineering, Educating the engineer of 2020: Adapting engineering education to the new century, Washington, DC: National Academies Press, 2005.

[11] Watson, K. "Change in Engineering Education: Where Does Research Fit? Journal of Engineering Education 98 (1): 3-4., 2009, 3.

[12] Sheppard, S. D., W. J. Pellegrino, M. B. Olds, "On Becoming a 21st Century Engineer", Journal of Engineering Education 97 (3): 231-38, 2008, 231

[13] Huang, D. (2001). An after-school evaluation system for middle and high school programs. NAASP Bulletin, 45(626), 45-61. doi: $10.1177 / 019263650108562605$

[14] Pieters, R., and Baumgartner, H. "Who Talks to Whom? Intra- and Interdisciplinary Communication of Economics Journals.” Journal of Economic Literature: 40(2), pp. 483-509, 2002, 2.

[15] Center for the Advancement of Scholarship on Engineering Education (CASEE). (2005-2006). "Progress and Accomplishments: Engineering Education Research and Development": Washington, DC: National Academy of Engineering.

[16] Kurzweil, Ray. (2005) The Singularity is near: when humans transcend biology. Penguin Group. New York, New York.
[17] Chickering, Arthur and Stephen C. Ehrmann (1996) "Implementing the Seven Principles: Technology as Lever," AAHE Bulletin, October, pp. 3-6.

[18] Chickering, A.W., \& Gamson, Z.F. (1987). Seven principles for good practices in undergraduate education. "American Association of Higher Education Bulletin", 3-7.Gibson, J. J. (1986). "The Ecological Approach to Visual Perception". Lawrence Erlbaum Associates, Inc. Hillside, New Jersey.

[19] Alabanese M., "Problem-Based Learning: why curricular are likely to show little effect on knowledge and clinical skills," Medical education, Vol. 34, No.9, 2000, P.729. doi:10.1046/ j.1365-2923.2000.00753.x

[20] Bransford, J., A. Brown, and R. Cocking. How people learn: Brain, mind, experience, and school. Washington, DC: National Academy Press, 1999.

[21] Christensen, Clayton. (208). Disrupting Class: How Disruptive Innovation Will Change the way the world Learns. McGraw-Hill: New York, NY.

[22] Gabriele, G. 2005. Advancing engineering education in a flattened world. Journal of engineering Education: 94(2):3-5.

\section{AUTHORS}

AKRAM ABU-AISHEH is an Associate Professor of Electrical and Computer Engineering at the University of Hartford where he has served as the assistant chair of the Electrical and Computer Engineering Department and director of the electronic and computer engineering technology program for two years. Dr. Abu-aisheh has a doctorate in Optical Communications from the Florida Institute of Technology and Master of Science and Bachelor of Science degrees in Electrical Engineering from the University of Florida. Dr. Abu-aisheh may be contacted at abuaisheh@hartford.edu.

LYNROY GRANT is an Assistant Professor of Technical Mathematics and Engineering Simulation at the University of Hartford where he has developed the evidence based Learner Agent Objects (LAO) methodology to foster mobility in twenty-first century engineering education. Dr. Grant has a doctorate in Education and Mathematical Sciences from the University of Connecticut, and Master of Science in Mathematics and Computer Science from Central Connecticut State University. Dr. Grant may be contacted at lygrant@hartford.edu.

Received April 13 ${ }^{\text {th }}, 12011$. Published as resubmitted by the authors May $2^{\text {nd }}, 2011$. 